\title{
The Place of Identity and Hybridity on Literary Commitment in Bessie Head's When Rain Clouds Gather
}

\author{
Elizabeth A. Odhiambo \\ Department of Linguistics, Languages and Literature, Jaramogi Oginga Odinga University of Science and Technology, Kenya \\ e.achieng39@yahoo.com
}

\section{Doi:10.5901/jesr.2015.v5n3p61}

\begin{abstract}
The current study examines the influence of identity on literary commitment in Bessie Head's When rain clouds gather. In particular, the study is interested in the hybrid syncretic crossings reflected in the text and which define her commitment as a writer in the Third Space - a dimension that has so far been overlooked by critics of her literary works. The study adopts the analytical research design. The postcolonial theory is instrumental in the reading, analysis and interpretation of the selected text. The data collected through content analysis of the text is coded according to thematic concerns, the mode of characterization and the vision of the author. The findings reveal that Head's identity influences her commitment in her choice of characters that like herself, are cast in the in-between space. These characters shuttle between points of inclusion and exclusion. Within this in-between or Third Space, identities defy fixity thereby remaining fickle, fluid and unstable. People are thus cast in a perpetual process of becoming, always mutating or changing into something 'other'. Essentialist formulations of identity are undermined by defiance of territorial confinement which allows for cultural fusion, but in the process also results in fission or more precisely, a shift from essentialist perceptions of self image. Hybridity, on the other hand, emerges as the coexistence of differences. In such cases, differences meet, mix and tolerate one another. However, it does not imply total erasure of cultural differences; its only impact is to blur the boundaries. Despite this, hybridity is propped by the author as the recipe for a perfect society.
\end{abstract}

Keywords: Identity, Hybridity, Literary commitment, Bessie Head.

\section{Introduction}

Identity emerges as a kind of unsettled space, or as an unresolved question in that space between a number of intersecting discourses (Hall, 1989). Likewise, hybridity is a concept that confronts and problematises boundaries although it does not erase them. As such, it always implies an unsettling of identities (Ang, 2003). Until recently, identity has been thought of as a kind of fixed point of thought and being, a ground of action that implies the logic of something like a 'true self'. On the contrary, with regard to the multicultural writer as in the case of Bessie Head, identity is a process; it is split, and is not a fixed point but an ambivalent one. It is the relationship of the other to oneself (Hall, 1989). This ambivalence is reflected in the hybrid syncretic crossings that characterize the choice and development of characters as well as the author's treatment of pertinent issues.

Grobman (2007) for instance, argues that texts by writers of color are multiply inflected hybrids that blur but do not erase cultural difference, thereby allowing for multiple crossings or intersections of meaning (sic). Hybridity commonly refers to the creation of new transcultural forms within the contact zones produced by colonization (Larangy, 2008). Hybridisation takes many forms including cultural, political and linguistic. In line with Grobman's view, the commitment of such writers may reflect hybrid syncretic crossing that constitute their subject matter. The multicultural text thus offers a model enabling us to refigure our understanding of difference and in the African context, to re-examine all African literature as interconnected nexus.

The current study therefore, examines the influence of identity on the literary commitment of Bessie Head, a colored, born in an asylum's hospital in South Africa, to a white woman who was considered mad; her father was black. Head was taken from her mother at birth and raised in a foster home until the age of thirteen. She attended missionary school and eventually became a teacher. Abandoning teaching after only a few years, she began to write for the Golden city post. As the political crisis deepened in South Africa in the 1960s, Bessie went to exile in rural Botswana where she remained in refugee status for fifteen years before gaining citizenship. It is in Botswana that her literary career blossoms. Her writings cover many aspects of her personal experiences as a racially mixed person, growing up without a family in South Africa (Bissell, 1996). 
Discourse on exiles and their experiences have generated multiple voices over time. According to Genetsch (2003), one of the most pressing problems for those forsaking their homes for a new country is the construction of new identity. In more accessible terms, the central concern for many who feel themselves uprooted is how to make life in the diaspora 'livable'. 'Livable' in this case can refer to an attempt to reproduce the old country in the new. However, it might also imply in some cases that the country of origin is happily discarded in favor of the country of adoption. In Genetsch's view, the implications of what 'livable' entails are negotiated along a spectrum of possibilities ranging from assimilation into a new culture to the retention of the old, or, put differently, along a continuum from sameness to difference.

Vileim Flusser (1984) talks of exile not only in the common form between cultures and nation states but also in terms of generations and time. He argues that exile not only promotes creativity but also that the person in exile will be objective in the way that the native cannot be. In Flusser's view, in order to make life in exile livable, 'one must process data and make sense of the information.' The exile's interpretation of new reality through old knowledge will certainly create something original rather than an already existing version of reality.

Flusser's argument finds credence in the fact that many prominent authors and thinkers have backgrounds of exile. However, in my view, not all conditions of exile allow room for creative thought. Creativity requires space and time. The exile that has a family to fend for will be preoccupied with the struggle to survive and so may not afford such luxury. In turn, they may not be able to create any significant change in their new environment.

Adopting a different view point, Said (1984) asserts that exile is strangely compelling to think about but terrible to experience. It is the 'unhealable rift between a human being and a native place, between the self and its true home; its essential sadness can never be surmounted.' For Said, though some people go to exile by choice, to be in exile is a social construction just as much as a physical fact. The memory of home and a native place, whether it is lost or left by choice will never disappear. From Said's perspective exile is accompanied by a sense of nostalgia which in my view reflects the exile's inability to completely belong.

Milani (2005) expounds the same view when he observes that exile means more than anything else, a painful reversal of one of our most common cognitive and emotional orders of familiarity. Exiles are said to be bifurcated or dual beings torn between memory and attachment to the past, a past that is paradoxically often reconstructed in our memories of a paradise lost and the sobering, sometimes strange reality of the present.

Milani's assertion implies that while in exile, the victim's imaginations of home are sometimes more grand than the reality left behind. In his summation, exile begets a discomforting disconnect between the constructs of the individual's memory, or their fundamental sense of who they are and the reality of a new identity they have to construct as members of Diaspora.

Bessie Head went to exile on her own free will, propelled to do so by the deepening political crisis in South Africa. This according to Genetsch (2003) is an attempt to make life livable. However, informed by the conflicting perceptions of home and exile raised by Flusser (1984), on one hand, and Said (1984) and Milani (2005) on the other, this study seeks to probe the possible range of identity construction in a postcolonial analysis of literary commitment. The aspect of construction implies that self- image does not rely on essentialist formulations but is in need of a difference against which to define itself whereas postcolonial means an attempt to come to terms with the disrupting experiences of colonialism, the question of identity inclusive.

At the turn of the century, hybridity had become part of a colonial discourse of racism. However, the crossover inherent in the imperial experience is essentially a two way process. According to Ashcroft, Griffiths and Tiffin (2003), postcolonial studies have focused on the nature of postcolonial culture as strength rather than a weakness. It is not a case of the oppressor obliterating the oppressed or the colonizer silencing the colonized. In practice, it stresses the mutuality of the process. The clash of cultures can impact as much upon the colonizer as the colonized. Multicultural fiction thus does not have to accept a cultural tradition or adopt it uncritically. It may well encompass stories in which the protagonists feel uneasy with their cultural tradition and modify or even discard it (Genetsch, 2003).

Homi Bhabha (1995) stresses the interdependence of the colonizer and the colonized. He argues that all cultural systems and statements are constructed in what he calls the 'Third Space of Enunciation.' Bhabha urges us into this space in an effort to open up an international culture not based on exoticism or multiculturalism of the diversity of cultures but on the inscription and articulation of cultures' hybridity. Bhabha, in this instance, hopes that it is in this space that we can find words with which we can speak of ourselves and others. And by exploring this Third Space we may elude the politics of polarity and emerge as the others of ourselves.

According to English (2002), the Third Space, a term originally coined by Homi Bhabha, is a concept used to describe the possibility for a negotiated reimagining of cultural identity. 'It refers to the constructing and reconstructing of identity, to the fluidity of space, to the space where identity is not fixed ... it is where we negotiate identity and become 
neither this nor that but our own'(n.p.). 'Third' is used to denote where negotiation takes place, where identity is constructed and reconstructed, where life in all its ambiguity is played out.

The Third Space therefore is an opportunity that opens up and broadens horizons and challenges ideas of polarity or binary distinctions, replacing either/or with both/and. Negotiating the Third Space entails listening and giving others the opportunity for self expression (Hannula, 2001). Importantly, there must be a commitment from both parties to grasping the opportunity.

The Third Space is thus considered as the contact zone within which different cultures encounter. Hybridity is an inevitable result of this cultural encounter. The Third Space results from the overlapping of cultures understood as 'hybrid' and can be understood as contact zones between cultures and as the encounter of spaces, which now as the product of translation between cultures can generate borderline effects and identification (Wolf \& Fukari, 2007).

Based on her biracial nature, I argue that Bessie Head's literary works are an expression of commitment in the Third Space, a zone where different cultures collide. The study assumes that due to her multicultural background and history of displacement, her commitment as a writer reflects hybrid syncretic crossings thus reveals an interesting dimension of the African novelist's literary commitment. This is inspired by the fact that her critics have so far overlooked an examination of how her multicultural identity possibly influences her commitment.

\section{Theoretical Framework}

The study is guided by the postcolonial theory. This is because post colonialism is the platform through which one can investigate issues of identity and commitment of the Third World writer. This theory deals with the writing and reading of literature written in previously or currently colonized countries or literature written in colonizing countries which deals with colonization or colonized people. Notable theoreticians in this field include Edward Said, Gayatri Spivak and Homi Bhabha among others.

The theory focuses particularly on the way in which literature by the colonizing culture distorts the experience and realities, and inscribes the inferiority of the colonized people. It also focuses on literature by the colonized people which attempts to articulate their identity and reclaim their past in the face of that past's inevitable 'otherness.' It can also deal with the way in which literature in colonizing countries appropriates the language, images, scenes, tradition and so forth in colonized countries (Lye, 1998).

For the purpose of this research it was useful in analyzing how identity influences commitment in Bessie Head's When rain clouds gather. Emphasis is laid on the comprehensive comparative model which argues for features such as hybridity and syncretism as constitutive elements of all postcolonial literatures.

\section{Literature Review}

Various scholars have studied Bessie Head's works with particular focus on the concept of identity and come up with varied views. Mhalahlo (2002) for instance, explores the perceived intricate relationship that exists between constructed identity, discrimination and violence as portrayed in Bessie Head's trilogy from varying perspectives including aspects of coloniality, materialist feminism and liminality. His major concern is with the affinities that exist between identity, discrimination and violence. The current study relates to Mhalahlo's to some extent in that it probes the possible range of identity construction in the text of study given the hybrid nature of the author. However, the difference lies in the fact that it proceeds to address other aspects of commitment as well.

Along the same line, La Rose (2005) examines the element of being and totality in Bessie Head's A question of power. He argues that while Marxist criticism may be instructive in its provocation of materialist literary analysis, these readings may obfuscate pertinent discursive issues of individual ontology. In his view, this literary conundrum is exemplified by $A$ question of power in which a Marxist critic may elucidate the protagonist's social-political reality. Nevertheless, it may also overlook several ontological questions which would be more appropriately examined through a 'pluralist' feminist critic that integrates several critical approaches: the significance of gender, the formation of individual consciousness as it appertains to feminist existentialism and the psychoanalytic and existential theories of Frantz Fanon: the dialectic of political power and Head's own universal moral idealism. The present study closely relates to La Rose's in that it too, revolves around the question of being and becoming and how this informs literary commitment. La Rose's view is also pertinent in that it recognizes the need for further studies of Head's works from varied perspectives; the only difference is that his argument is limited to $A$ question of power only.

Adding to the debate on identity, Dieke (2007) argues that Head's Maru, more than A question of power distils the 
very essence of her creative enterprise laced with an overriding concern for an investigation into the enigma of human prejudice. He points out that although $A$ question of power can be said to be an important site for unraveling the strands of her anguished life story with instances of immense suffering, privation and crippling alienation, Maru, on the other hand, provides the fertile site for mounting a literary resistance to the mistaken ideology which often gave rise to the anguished life story. For, without this insane ideology there would not be crippling alienation. Without this ideology there would not be suffering and privation. Both the ideology and its accoutrements represented the same morbid state. The current study however examines When rain clouds gather with regard to how identity informs commitment in the text contrary to Dieke's which is limited to results of human prejudice.

From the above review, it is evident that various studies have been conducted on Bessie Head's works with regard to the question of identity. However, no scholar has so far focused on how her identity influences her literary commitment, thus the interest of this study.

\section{Methodology}

The research was mainly qualitative. It was conducted through an analytical research design. Analytical research, as a style of qualitative inquiry is a non interactive document research which describes and interprets the past or recent past from selected sources (Macmilliam \& Schumaher, 1997). These sources may be documents preserved in collections or participant's oral testimonies or as in the case of this research, a literary text of an author. This design is ideal in a situation where a researcher attempts to analyze a situation and make evaluation. For the present research, it was instrumental in examining the influence of identity on Bessie Head's literary commitment.

\subsection{Data Collection Techniques}

The study was mainly library based. It began with a preliminary study of the available related literature in the library which formed the basis for secondary data.

The primary data was generated through content analysis of the selected text. Nachmias (2009) defines content analysis as any technique for making inferences by systematically and objectively identifying specified characteristics of messages. Qualitative content analytical approaches focus on analyzing both the explicit or manifest content of a text as well as interpretations of latent content of texts- that which can be interpreted or interpolated from the text, but is not explicitly stated in it (Granhein \& Lundman, 2003).

In the current research, reading, analysis and interpretation of the selected text was done to establish the extent to which the writer's identity influences her literary commitment. This was accomplished through use of the postcolonial theory.

\subsection{Data Analysis}

The data collected through content analysis of the selected texts was then coded according to thematic concerns, the mode of characterization and vision of the author. The more comprehensive comparative model of the postcolonial theory which argues for features such as hyridity and syncreticity as constitutive elements of all postcolonial literatures was applied in the textual analysis to establish the hybrid syncretic crossings in the author's works.

\section{Identity and Commitment in When Rain Clouds Gather}

The main character in When rain clouds gather, Makhaya Maseko crosses the border from South Africa into Botswana. This, in his view, is a measure to help him rebuild his shattered life. So firm is he in his resolution that he spends a whole day holed up in a small hut built very close to the barbed wire fence that separated Barolong village from Botswana. His intention is to wait for darkness to fall so that he may try to spring across the Botswana border to whatever illusion of freedom that lay ahead.

Ashcroft, Griffiths and Tiffin (2002) observe that the dialectics of place and displacement is always a feature of postcolonial societies whether these are created by the process of settlement, intervention or a mixture of both. Incidentally, this is the motif around which the text When rain clouds gather is woven. This thus is in tandem with the deployment of postcolonial theory as the lens through which to examine the text as will be the case in this study. In the three scholars view, it is in the concern with place and displacement that the special postcolonial crisis of identity comes 
into being particularly the concern with the development or recovery of an effective identifying relationship between self and place.

The quest for a redefinition of identity is visited right at the onset of the story. Symbolically, the in-between location of the hut in which Makhaya is holed up at the border of Barolong village and Botswana alludes to the element of fluidity in identity. Presently, Makhaya is at the point of transition. Within the confines of this hut, he is a fugitive. His intention is to discard this present identity and attain freedom. The hut and the caution with which he departs from it is what will determine the identity he will adopt thereafter. This hut, besides being a physical manifestation of the precariousness of Makhaya's current position in the in-between world, may be seen as an agent of transformation of identity, not just for Makhaya, but for several other fugitives who stop there over time. Its circular wall that stretches up to the barbed wire fencing depicts a continuous preoccupation with the search and redefinition of identity. Identity is thus depicted as fickle, fluid and unstable. This by extension depicts the writer's preoccupation with transformation.

Indeed, Makhaya's plunge into the unknown is an effort at constructing a new identity. Already, the shattering experience he has undergone in his home country has destabilized his composure. The exploration of the journey motif which entails crossing borders emphasizes the process of change. Crossing borders reflects defiance of territorial confinement. The quest for a new identity is however revealed as threatened by insecurity and uncertainty that surrounds the people's life. This is highlighted by the patrol van of the South African border police that sped past every half hour with its sirens wailing. Its impact is reflected in the unpleasant sensation it causes in Makhaya's stomach.

Through the construction of Makhaya, Head finds a vent through which she expresses a personal experience. Like her protagonist, she too had quit South Africa on an exit permit to seek refuge in Botswana amid tumultuous challenges. The description of Makhaya's appearance brings out a sense of ambivalence, 'his long thin falling away cheekbones marked him as a member of either Xhosa or Zulu tribe'(p1). Again like her protagonist, Head's appearance as a colored also cast her in an in-between position, at one point she is even discriminated against by fellow coloreds who found her a bit too dark for their liking. In Makhaya's case, the old man in whose hut he seeks refuge screws up his face when he tells him his name since the sound and meaning of the name were unfamiliar to him. He then declares his inability to peg the name to any particular ethnic community, all the while shaking his head in confusion. Makhaya finally solves the puzzle for him by revealing that he is of Zulu tribe.

Contrary to the proclamation that he is a Zulu, Makhaya speaks Tswan very well. This difficulty in pegging him to a specific ethnic community based on his physical appearance gives him a malleable identity thereby reflecting the instability of identity. Physical appearance emerges as quite deceiving. By way of explanation, Makhaya says, 'Yes we Zulu are like that. Since the days of Shaka we've assumed that the whole world belongs to us; that's why we trouble to learn any man's language'( p3). However, he goes further to blame his name on his tribalistic parents, 'I'm no tribalist. My parents are - that's why they saddled me with this foolish name. Why not call me Samuel or Johnson, because I'm no tribalist' (p3). In Mahkaya's view a tribal name accorded one a tribal identity and by extension defined the opportunities at one's disposal as dictated by the tribal expectations. This perspective gives credence to Hogg and Abrams (1988) who view identity as a people's concept of who they are, of what sort of people they are, and how they relate to others.

In as much as Makhaya denounces tribalism as a social evil that results in exclusion in his effort to define a new sense of belonging, he acknowledges this new effort as originally tribalistic. It is a culture that was inculcated in the people during Shaka's legacy and is therefore tribal in nature. To proclaim his connection with Shaka is to authenticate his rootedness in the tribe. It concretizes his link with his roots. It is therefore ridiculous for him to try to dissociate himself from his tribe. The other option proposed - to be referred to as Samuel or Johnson, which for him are typically non tribal names, reveals his naiveté since the two names are in fact tribal. The name Samuel is Jewish whereas Johnson is English in origin. Adopting the foreign names would therefore result in the mimicry of a foreign culture. In this way, Makhaya shuttles between a sense of belonging and exclusion.

He imagines that to adopt non-African names would make him non-tribal yet in reality he would be suppressing his own cultural identity. The old man blames education for contributing to Makhaya's alienation. Without education, Makhaya would have easily fitted in the traditional lifestyle by simply marrying a tribal girl and participating in daily communal activities without feeling discontent. Education thus alienates one from his tribal identity. The victim finds himself thrown in an in-between space professing a tribal identification tag expressed by the name but at the same time resisting conformity to a tribal perception and lifestyle.

This challenges the notion of hybridity. Instead of blending cultures, victims are threatened with obliteration. This in essence emphasizes the domination of the foreign culture over the native self. The victim glorifies the exotic as opposed to the indigenous thereby reflecting the extent of his naiveté. He is trying to run away from himself yet imagines that this reflects his mental liberation 
Further hitches are encountered in the quest for a sense of belonging. For Makhaya, Botswana had belied a promise of serenity if only he could reach this safe haven. However, the state of insecurity also pervades this territory thus mistrust reigns. The old woman whom he approaches for shelter immediately labels him 'spy'. She burst out in a loud jarring voice questioning why anyone who was not a spy would wander at night. In her view, all the spies in the world were coming into her country thus her insistence that Makhaya was a spy. This proclamation authenticates a notion of 'Otherness' perpetuated by ethnic difference.

Even though Makhaya is among people of his race, he is still excluded from them by suspicion. This is testimony to the fact that even within an ethnic community, dissenting voices may arise. The author thus contributes to creating cultural representations that challenge the view of a homogeneous African society. By extension, highlights the view that immigrants' efforts to integrate themselves in their new-found homes, do not always meet with total acceptance. In most instances, they may meet a rebuff from the natives of the host country who view them as intruders. The quest to belong is thus always encumbered with challenges.

Makhaya's experience with the old woman is reminiscent of Head's personal experience in exile. Initially, she had been naïve enough to believe that because she was eager to be part of the village life believing that she had at last found a place where she could settle and build up her life, and that the villagers also wanted her to be integrated with her dictating the terms. She was shocked to realize that they regarded her as an outsider since unlike them, she appeared quite sophisticated.

The depiction of moral disintegration in the society is characterized by a double imperative. Previously, Makhaya had blamed it on the dehumanizing conditions imposed on the blacks by the oppressor. 'He thought that they were created by poverty and oppression, and had spent the last two years in jail in the belief that, in some way, a protest would help to set the world right'(p10). As a result, the old hag's mentality jolts him out of his reverie. He realizes that greed too pushed individuals to commit evil. The blame could be cast upon the oppressor as well as the oppressed. The old woman for instance, uses the small girl in her custody to extort money from male strangers in exchange for sexual favors. The small girl is so used to this procedure that she readily complies. Makhaya is first surprised by the unchildlike stare she gives him. As if this is not enough she is reluctant to leave him alone when he asks her to do so emphasizing the fact that her grandmother would not mind as long as she got paid.

From this encounter, Makhaya is awakened to the shocking realization that it was not only the external oppressive forces that stripped individuals of the moral fabric but the traditional code too. He is repulsed by the perception of a man as nothing more than 'a groveling sex organ, that there was no such thing as privacy of soul, and that no ordinary man would hesitate to jump on a mere child' (p10). Yet such mentality was so inscribed that to change them would be difficult. The old hag for instance, is so surprised that any virile man would turn down such an offer unless they were mad. She exclaims, "This is a miracle! I have not yet known a man who did not regard a woman as a gift from God! He must be mad (p10). Makhaya thus finds himself at crossroads. His reason for leaving his home had been to find a part of the African continent that was not mentally and spiritually dead through the constant perpetuation of false beliefs. Ironically, his confrontation with the hag revisits the same mentality.

Makhaya's in-between position is emphasized in his confession to Dinorego. Asked whether he is stranded, he says, 'Well educated men often come to the crossroads of life. One road might lead to fame and importance, and another might lead to peace of mind. It's the road of peace of mind that I'm seeking' ( $p$ 15). This is a confirmation that education broadens horizons and levels of interaction for individuals. It casts the victim in a realm of intercultural encounters with an array of pursuits to choose from due to extended interaction. Such characters operate within the Third Space; a space of mutual borrowing when cultures meet, intersect and blend though the cultural differences may not be completely erased. Makhaya, for instance, wrestles with his conscience, debating between peace and fame.

The choice of Golema Mmidi as the stage of action is a deliberate attempt by the author to explore issues of identity. This becomes Makhaya's haven, as well as a haven for several other individuals who had fled there to escape the tragedies of life. The uniqueness of the village stems from the fact that it is not a village in the usual meaning of being composed of large tribal or family grouping. Its name also marks it out from the other villages which are named after important chiefs or important events. Instead it acquires its name from the occupation of the villagers, that is, crop growing. To live in Golema Mmidi thus pegs no definite identity to the inhabitants. The village, by virtue of its diversity, may be construed as a Third Space- a space of hybridity convenient for cultural translation and blending.

The choice of such a village as a scene of action of the story is a conscious attempt at establishing points of intercultural encounter. In this space, individuals of various ethnic divides encounter and attempt to make meaning of life. This choice may also be seen as the writer's attempt to relive her personal experience as a refugee since Gilbert's farm in the text is reminiscent of the Bamangwato Development Association farm at Radisele where she had worked for some 
time. This, by extension, is a proposal for cultural fusion. Blending, characteristic of hybridity, gives individuals a sense of rejuvenation as a result of borrowing and translation of cultures. It allows the individuals a taste of new experiences that helps them recreate their lives through exposure to new stimulus.

At Golema Mmidi, the inhabitants' strength lies in their diversity. As a result, the arrival of Gilbert, a white, creates no tension among the villagers. They find his unique ideas fascinating. Perhaps this is so because they too had come from far off lands. He is depicted as the chief proponent of change through his entrepreneurial skills. He advocates corporative farming and cattle rearing. This would be a reasonable alternative to the nomadic way of cattle rearing which demanded a lot of space particularly in view of harsh weather conditions. Within this space, difference is regarded as a resource from which all other parties can reconstruct their lives, and by extension, reconstruct their identity. This reflects the dynamism of fusion. It results in a process of continuous transformation. Identity is thus depicted as defiant of fixity. It is in a perpetual process of becoming, always mutating and transforming to give way to new creations.

The portrayal of Gilbert also demonstrates an attempt to establish a common ground between cultures and subsequently attempts at hybridity. He is white and comes all the way from England because of what he had observed during his previous visit to Botswana. On his return to England after this visit to Botswana, he takes a Diploma in agriculture with the intention of going back there to help in agricultural development and food production. To him, the country presented overwhelming challenges not only because the rainfall was poor but because the majority engaged in subsistence farming were using primitive techniques that ruined the land. Based on his knowledge of modern agricultural techniques, he is portrayed as the destined savior of a community stricken by hardships. These hardships were attributed to the harsh weather conditions as well as the people's ignorance.

Gilbert's interest in improving life in Botswana despite his Western descent is an attempt to bridge differences by uplifting living standards of the natives. However, his race and supposedly superior knowledge places him at a position superior to that of the natives. This is because the natives' ignorance stands in the way of their own progress. It takes a foreigner to help them solve problems that affect them within their own land. Viewed connotatively, this implies domination of one culture over the other. The supposedly inferior culture is 'swallowed up' by the foreign culture. This presents challenges to reconstruction of identity. Instead of paving way for blending through syncretism, the result is the overpowering of one by the other. This makes differences starker since the fault lines are made more prominent.

At another level, attempts at syncretism are revealed when instead of being alienated from the natives on the basis of his race and knowledge; Gilbert is depicted as friendly and down to earth. In Dinorego's opinion, Gilbert was different since he could eat goat meat and sour milk porridge which Dinorego had not known a white man to eat before. In addition, Dinorego has a lot of respect for Gilbert's ideas all of which for him portend progress. Noteworthy too is the fact that Gilbert seeks advice from Dinorego whenever there is trouble. In this regard, knowledge is portrayed not as a preserve of any particular race since in Dinorego, Gilbert recognizes wisdom and Dinorego in turn regards Gilbert as a son. The distinction between the two however lies in the fact that each is a master of his own world which in each case is foreign to the other. This in turn challenges the prospect of absolute syncretism. Gilbert's relationship with Dinorego thus highlights the benefits of cultural tolerance.

The close interaction between Gilbert and Dinorego may be seen as the writer's design to blur cultural boundaries. However, Gilbert's superior knowledge alerts us to the difficulty of erasing such boundaries. The fault lines will always remain. Dinorego is wise in the African way of life yet he almost worships Gilbert because in his perception, progress by the African can only arise from knowledge derived from the Whiteman as represented by Gilbert. He is therefore ready to draw as much knowledge as possible from Gilbert to blend with his own so as to as to progress. Hybridity thus confronts and problematises boundaries, although it does not erase them.

Maria's marriage to Gilbert is an attempt at syncretism through fusion of the black and white race. This may be construed as Head's utopian solution to cultural differences through miscegenation. However, it emerges that crosscultural relationships do not always imply a total merging of cultures. This is exemplified by Maria's answer to Mma Millipede in response to why she had delayed her marriage to Gilbert for three years. She says:

Gilbert is a man with many strange ways. A person has to get used to these strange ways. For some time now he has kept a lizard in the house whom he treats as a person and which is now accustomed to being spoken to. Its name is skin. Each night it is put down beside the lamp to have a meal off the insects that gather there. Also I have often seen it asleep on the pillow like a child, with its legs spread out. Gilbert does not live in this world but in some world about which I know nothing (p 91).

Maria's statement is a confirmation of the difficulty of erasing cultural differences. She has related with Gilbert for three years but is still unable to fully comprehend his strange ways. To treat a lizard as a person and even talk to it is 
alien to Maria's world. On the contrary, her father Dinorego finds Gilbert acceptable, unlike other white people because to some extent, he has adapted to the ways of the native people particularly their eating habits. The concept of hybridity thus allows for cultural crossings without necessarily erasing the underlying culture. It may well imply tolerance of differences. Thus within the new transcultural zones, individuals acquire new characteristics borne out of new experiences without necessarily dismantling the underlying culture. Maria's acceptance of Gilbert's marriage proposal does not amount to total syncretism but is a union based on mutual understanding of differences.

Cultural syncretism also presents a lot of challenges. Maria, for instance, likes all things modern. In an attempt to achieve this modernity, she also takes lessons from Gilbert in English. She even goes further to curve shelves in the mud walls of the kitchen in imitation of the shelves she had seen in a picture book given to her by Gilbert. In addition, she now cooks goat meat with curry powder to improve its taste. Despite all these attempts to bridge the cultural boundaries, she still acknowledges the fact that Gilbert lives in a world that she knows nothing about. Her efforts at inclusion thus result to exclusion since she cannot completely immerse herself into Gilbert's world. Their marriage is thus based on coexistence of differences.

This sentiment is emphasized by Mma Millipede. Earlier on she had suspected that there was more than met the eye in the relationship between Maria and Gilbert. The only thing that had prevented her from voicing her suspicion to Dinorego was the fact that 'Gilbert was a foreign man and foreign men were a fearful unpredictable quantity in an otherwise predictable world' ( $p 73$ ). To sum up foreign men as a fearful unpredictable quantity is to confirm the impossibility of absolute syncretism.

The relationship between Maria and Gilbert is thus constituted in the Third Space; it oscillates between points of inclusion and exclusion. Maria in an attempt to embrace change mimics a foreign culture which however, she cannot fully embrace. Likewise, Gilbert's effort to bridge the gap demands that he shifts his cultural position to meet the natives halfway. However, this shift does not guarantee total acceptance. He is confronted by the African oppressor Matenge who sees him more as a competitor and sets out to make his life as difficult as possible. This throws him off balance and results in many sleepless nights. In particular, he is unable to 'understand the workings of an extremely cunning and evil mind, a mind so profoundly clever as to make the innocent believe they were responsible for the evil' ( $p$ 26). This presents itself in the person of Matenge, the sub chief. Absolute syncretism thus remains an illusion. Identity remains unsettled, unable to succumb to a specific definition.

The association between Gilbert and Makhaya and their complimentary predisposition marks an attempt at cultural hybridity. In the three years Gilbert had spent in Golema Mmidi, he had realized his own limitation in putting his ideas across to people. Most important, he had learnt that 'change if it was to take place at all, would in some way have to follow the course of a people's life rather than impose itself in a sudden and dramatic way from on top' (p26). In addition, he had realized that he did not have the kind of personality that could handle people because everything in him was submerged to the work he was doing. He also lacked sympathy, patience and understanding thus a complimentary personality that would make up for his deficiency was necessary. This is realized through Makhaya who unlike Gilbert, had the ability to make people feel at ease and was therefore a more effective teacher. This complimentary relationship between Makhaya and Gilbert emphasizes the need for harmony and mutual respect in relationship. In essence, hybridity emerges as the coexistence of differences.

Also, in as much as the two characters' complimentary nature symbolizes hybridity, the paradox to this coexistence is presented in the symbolic reference to Gilbert as 'the sun' in recognition of white superiority. Just like the 'sun knew why the clouds formed and why the wind blew and why the lizards basked in its warmth and all this immense knowledge made the sun gay and bright, full of trust and affection for mankind,'( $p$ 83) so did Gilbert pride himself on being an unusually well-informed man. Makhaya's world, on the contrary, is likened to the 'shut away worlds where the sunlight never penetrated, haunted worlds full of mistrust and hate, and it was about this world that Makhaya was particularly well-informed' ( $p$ 83). The glaring contrast between the two characters' worlds may be symbolic of the two continents from which the two hail. Gilbert is of the First World whereas Makhaya is of the Third World. The Third World thus relies on assistance from the First World to salvage it from total darkness by shining its light upon it. The association between the two characters thus metaphorically depicts interplay of power relations between merging poles.

From the postcolonial perspective, the juxtaposition of Gilbert and Makhaya is the writer's way of affirming the notion of imperialism in Africa. The colonial powers inscribed the inferiority of the colonized by imposing their foreign cultural values and perceptions on them. They perpetuate the Third World's dependence on them on the pretext of assisting them through grants. In return, they exploit the resources of the African continent. The reference to Gilbert as the sun acknowledges white superiority. Africa, on the other hand, is designated the 'dark continent' equated with backwardness and barbaric practices. On the contrary, just as is the same with the daily alternation between light and 
darkness to create a full day, in the morning, light swallows up darkness to give room to day whereas in the evening, darkness swallows up light to pave way for night. The two situations, light and dark are essential components of day. This metaphorically, strengthens the bargain for a need for coexistence between cultures.

This total contrast in their world views calls for a compromise to which Makhaya agrees. Such a compromise is necessary for positive development in their activities. Their relationship thus dramatizes a conscious choice to coexist. Initially, Gilbert had been fearful of being critical of the African way of life which seemed to him a deadly chilling society which kept out anything new and strange. In his view, the people's greatest fear was to be different from the next person. For Gilbert thus, Makhaya was a bridge between the native and the exotic. In particular, Makhaya's proclamation that his was just a tribal name and that Gilbert could call him Mack if he liked had immediately caught his attention. In Gilbert's judgement, their handshake thereafter may be construed as a moment of bonding. For Gilbert, Makhaya's was 'the first real hand clasp he had experienced in the loneliness in which he found himself in tribal Africa' ( $p$ 25). This feeling is attributed to the fact that Makhaya unlike the rest is not bound by tradition. Head in this way seems to stress the need to break from the bounds of tradition if one was to achieve freedom and success.

To ensure the success of his projects, it mattered very much to Gilbert to have 'as a friend a man who looked as black as everyone else and yet was not at all a part of these chilling group attitudes' (p104). Makhaya's personality was ideal since it radiated a gentleness that communicated itself as strength and gave peace to others. He also had 'a complete lack of fear and a background of persecution which made it so easy for him to identify with the rugs and tatters of the poor' (p104). Makhaya thus complements Gilbert. Indeed it is through him that Gilbert is able to achieve his objectives. His ability to make people feel at ease is particularly instrumental to the establishment of the tobacco project. The small group of women he addresses at first feels a little inhibited for they are unaccustomed to a man talking to them as an equal. They stand back awhile, with uneasy expressions. It is only when it strikes them that Makhaya paid no attention to them as women that they also forget that he is a man and become absorbed in his explanations. Respect between genders thus blurs boundaries creating a possibility for mutual interaction.

Makhaya's interaction with Gilbert also changes his opinion of the white man. Ordinarily the relationship between the blacks and the whites was highly polarized. Thus like other blacks he had been accustomed to reacting in only one way to a white man and that was with a feeling of great unease yet with Gilbert, he felt completely at ease. As Head observes:

\begin{abstract}
... few black men in their sane mind envied or cared to penetrate the barrier of icy no man's land which was the white man and his world. The black man preferred to retreat to his own world among the garbage and filth and worse, where a lot of people will be real and familiar and to whom your reactions would be such as to fill you with a sudden flood of relaxed warmth (p129).
\end{abstract}

The white man's world was something completely incomprehensible to the black man. As a result, the black man opted to operate within familiar territory among the garbage and filth. Within this territory there are no pretensions for it is here that the black man enjoys a sense of belonging. Makhaya's contrary feeling towards Gilbert owes largely to Gilbert's 'generosity, of soul and mind. Theirs is a friendship that is constructed in the Third Space in the sense that Makhaya's bid to attach meaning to life involved attempts to construct for himself an identity that is largely in conflict with the desires of his own people. Everything he desired and needed seemed to be needed by no one else in his own environment, among his own people or clan. It is this sense of alienation that makes him reach a compromise with Gilbert. Negotiation of identity thus begins with a kind of fission - a split or severence from essentialist definitions of identity. This is exemplified by Makhaya's defiance of essentialist formulations of identity defined by the tribe to create a unique image of himself.

This desire to break from traditions, maps out his new identity. It was only once his father had died that he was able to come forward with his own strange Makhaya smiles and originality of mind so that the end result was 'a new young man who stood there quiet and dignified, gentle and relaxed'. Makhaya's attitude thus undermines essentialist formulations of identity. His craving for difference is a recognition of the need to reach out and unchain himself from purist ideologies. The fact that there was nothing in his own environment to account for all the secret development that had taken place in him can be viewed as a criticism of tribalism and adherence to unfounded prejudices. Such practices denied individuals space for independent decision. The clamor for conformity as emphasized by tradition only emphasizes a tribal identity yet Makhaya prefers to chart his own unique path towards freedom.

The quest for a new identity thus casts Makhaya in the Third Space. He operates at the border of his society. Shuttling between a deep hatred for the white and respect for Gilbert. His reference to himself as a 'black dog' in a conversation with Mma Millipede reveals that deep within him, he nurtures a deep and bitter hatred for the white man and foresees a time when the black man will revolt against the white oppressor. The Christian view of salvation meant that 
the white man will forever go on slaughtering the black man because Jesus Christ will save him from his sins. In Makhaya's view, Africa could do without such a religion. His relationship with Gilbert however thaws part of this bitterness, for it is only through Gilbert that he discovers in himself a compassion for the whole great drama of human history. Hybridity is thus depicted as a site for social renewal. It exposes individuals to new and progressive ideas outside their own world view. In this way, hybridity creates space for a wider understanding of mankind as well as the need to improve oneself. Above all, it thrives on mutual understanding of differences.

Makhaya's scrutiny of Gilbert's culture also reveals to him gaping holes in his own culture and how impossible it would be for Africa to stand alone. This deduction emphasizes the need for coexistence of differences, implied in the hybrid conception of the world and subsequently, the globalization of culture. He is dissatisfied with his African cultures which, in his view, lacked almost entirely this love and care for the earth and instead directed its interest towards people. Makhaya does not fit within this framework because he has an inclination for his own company thus Gilbert's scientific outlook is a welcome alternative to him. He finds himself beginning over this time to combine the two cultures- the good in Gilbert and the good in his own society. The attempt to blend the two cultures is an effort to blur binary distinctions. This in itself points towards cultural syncretism, and by extension, a preference for cultural fusion.

The relationship between Makhaya and Paulina is also constructed in the Third Space. This is so because the two characters hail from different backgrounds. Paulina is a Northerner whereas Makhaya is South African. Paulina adores Makhaya but Makhaya deliberately respects the social distance between them. This is a strategy to keep all admirers at bay. Thus Paulina's first attempt to draw Makhaya's attention is rebuffed by him. He is careful to keep himself the 'homeless foreign alien' (p147) though he is aware of Paulina's feelings for him. In his view, this emotional detachment is essential to real love and respect. Through this relationship, the need to exercise caution before engaging in binding relationships is emphasized.

Besides his aloofness, Makhaya is also bent on breaking traditional barriers whereas Paulina has a traditional outlook. In one instance, Makhaya offers to make tea and goes about implementing his wish. To Paulina, making tea is a woman's job. For a man to cook as Makhaya does is thus alien to Paulina's world since this violated the boundaries of traditionally prescribed gender roles. Earlier on, he had instructed his sisters to call him by his name and to treat him as an equal contrary to tradition. When their relationship finally takes root, Makhaya instructs Paulina not to slosh tea on the saucer and to wash the little girl, Lorato every day. 'Even homes of mud must run like a hotel with everything spick and span and the small girl ought to be bathed from head to toe every night' (p182). These instructions definitely imply a sophistication that Paulina is unaccustomed to.

Ironically, Makhaya still observes the African custom of just coming and staying with a woman first without marrying her and then being indefinite about the date of marriage which might take place even after two or three children have been born. Much as this may be seen as an attempt to identify with his roots, Makhaya is set apart from other African men by the way he loved his wife. Love in this context implies sticking to one woman. As Head highlights, 'African men, liked the woman who stayed up the hill, and the one in the valley and the one in the next village, all in the same nice indiscriminate way" (p181). Yet to all this Makhaya is an outsider.

Makhaya's ideals thus depict a merging of two worlds. He thus shuttles between the exotic and the traditional outlook. At one point he appears to be completely alienated from his culture yet in the next instance, we find him tethered to tradition as is the case with regard to his view of marriage. His attempt to combine the best of both worlds is thus geared towards fusion, which in essence epitomizes hybridity, but at the same time, results to fission, reflected in his split with the indigenous tradition. Identity is thus depicted as being in a constant state of flux, thereby unstable.

Cultural fusion however, emerges as a way of enhancing individuals' lifestyle. It allows people to improve themselves by adopting elements of both lifestyles. At the same time fusion is only possible after fission or in certain instances, after a shift from essentialist perceptions of self image. Construction of identity thus implies an endless interplay of fissions and fusions dependent on the individual's encounter with and reaction to new experiences.

Through Mma Millipede binarity results in hybridity. In this case, differences meet, mix and tolerate one another. This is projected through her religious convictions. Ordinarily women lived idly in the village during the dry season while the men were busy with cattle the year round. In order to fill in the dull round of the day many women drifted to church where they also obtained a bit of missionary education. However, despite having this advantage over the men, majority of the women remained unchanged. 'They remained their same old tribal selves, docile and inferior' (p68).

Mma Millipede on the contrary turns out differently. Her contact with missionary education results in the redefinition of her identity. She is able to grasp the religion of the missionaries and use its message to adorn and enrich her own originality of thought and expand the natural kindness of her heart. This transformation offers a challenge to the conservative image ordinarily projected by women. In this way, Mma Millipede's interaction with missionary education 
results in the formation of a hybrid identity considered to be more progressive and essential for combating challenges. Hybridity is thus reflected as a site for social renewal.

\section{Conclusion}

From the discussion above, identity and hybridity influence the writer's commitment in the selected text; it is evident that Head chooses characters that like herself are cast in the in-between space or Third Space. In certain instances, the character's experiences resonate with the author's personal experiences. Some of them relocate to new places as an effort to try to reconstruct their identity, a situation that finds likeness with the writer's own experience since she too spends most of her life in exile. This is true of characters like Makhaya, Paulina, Gilbert and Mma Millipede.

Also, identity emerges as being in a constant state of flux. People are thus cast in a perpetual process of becoming, always mutating or changing into something 'other'. Essentialist formulations of identity are undermined by defiance of territorial confinement which allows for cultural fusion, but in the process also results in fission. At the same time, fusion is only possible after fission or more precisely, after a shift from essentialist perceptions of self image. This is clearly illustrated by Makhaya's attempt to redefine his identity. It emphasizes the writer's commitment to change.

Within the in-between or Third Space, identities defy fixity thereby remaining fickle, fluid and unstable. The quest for a universal identity that defies definitions of race or tribe is shrouded in shackles of prejudice enshrined in certain discriminative traditional outlook which must be dismantled or modified for one to attain total liberty.

Construction of identity thus implies an endless interplay of fissions and fusions dependent on the individual's encounter with and reaction to new experiences. Hybridity, on the other hand, emerges as the coexistence of differences. Put differently, binarity results in hybridity. In such cases, differences meet, mix and tolerate one another. This is exemplified by characters who imbibe new ways which they then blend with their own and use to improve themselves. Mma Millipede, for instance, is able to grasp the religion of the missionaries and use its message to adorn and enrich her own originality of thought and expand the natural kindness of her heart. Thus, within the spaces of hybridity, difference is regarded as a resource from which all other parties can reconstruct their lives, and by extension, reconstruct their identity. This reflects the dynamism of fusion. It results in a process of continuous transformation.

Hybridity is thus depicted as a site for social renewal. It exposes individuals to new and progressive ideas outside their own world view. In this way, hybridity creates space for a wider understanding of mankind as well as the need to improve oneself. Above all, it thrives on mutual understanding of differences.

However, the characters' quest to belong often results to exclusion. These characters therefore shuttle between points of inclusion and exclusion. Hybridity thus does not imply total erasure of cultural differences; its only impact is to blur the boundaries. Absolute syncretism is therefore an illusion since the fault lines still remain. Despite this, hybridity is propped by the author as the recipe for a perfect society.

\section{References}

Ang, I. (2003). Together in difference beyond Diaspora, into hybridity. Asian Studies Review, 27(2), 149-50.

Ashcroft, B., Griffiths, G., \& Tiffin, H. (2002). The empire writes back: Theory and practice in postcolonial literatures. (2nd ed.).London: Routledge

(2003). Post-colonial studies: The key concepts. London: Routledge.

Bhabha, H. K. (1995). Cultural diversity and cultural difference. In Ashcroft, B., Griffiths, G., \& Tiffin, H. The post-colonial reader. London: Routledge.

Bissell, K. (1996). Bessie Head. Retrieved October, 22, 2012 from: www.english.emory.edu/Bahri/Head.html

Dieke, I. (2007). Bessie Head's Maru: identity, pathology and the construction of difference. Western Journal of Black Studies. Retrieved from: http//findarticles.com/p/articles/mi-go2877/is-2-33/ai-n3216583/?tag=content;col1

English, L. (2002, May/June). Third Space:Contested spaces, identity and international adult education. Paper presented at the CASAE/ACEEA 21st Annual Conference

Adult Education and the Contested Terrain of Public Policy, Toronto, Canada.

Flusser, V, (1984) Exile and creativity. In Ströhl, A. (Ed.) Vilèm Flusser - writings, Minneapolis: University of Minnesota press

Genetsch, M. (2003). Difference and identity in contemporary Anglo-Canadian fiction: M. G. Vassanji, Neil Bissoondath, Rohinton Mistry (Doctoral thesis, Trier

University,2003). Retrieved from http://ub-dok.un-trier.de/diss/diss25/20031104/20031104.htm

Graneheim, U., \& Lundman, B. (2004). 'Qualitative content analysis in nursing research: Concepts, procedures and measures to achieve trustworthiness.' Nurse Education Today. 24(105-112).

Grobman, L. (2007). Multicultural hybridity: Transforming American literary scholarship and pedagogy. Retrieved November, 2011. 
From: https://secure.ncte.org/store/multicultural-hybridity

Hall, S. (1989). Ethnicity: identity and difference. Radical America. 23, 9-20.

Hannula, M. (2001). Third Space: Merry go round of opportunity. Kiasma Magazine, 12(1) Retrieved March 13, 2012 from: http:www.kiasma.fi/www/viewresource.php?lang=en\&id=3LoHIn6PkQfTgv09

Head, B. (1968). When rain clouds gather. London: Heinemann.

Inkas, K., \& Wagner, G. (Eds.). (2008). Communicating in the Third Space. New York: Rutledge.

Larangy, E. (2008). The imperial archive: key concepts in postcolonial studies. Retrieved November, 2014 from: www.qub.ac.ukl schools/.../imperial/.../hybridity.htm

La Rose, P. (2005). Being and totality: ontology and universality in Bessie Head's A question of power. Stirrings Still: The International Journal of Existential Literature. 2 (1). http://stirrigs-still.org/vol 2 no1.pdf

Lye, J. (1998). Some issues in postcolonial theory. Retrieved from: http://www.jeeves.brocku.ca/english/courses/4F70/postcol.php

Macmillian, J., \& Schumacher, S. (1997). Research in education: A conceptual introduction (4th ed.). New York: Harper Collins College publishers.

Mhlahlo, C.L. (2002). Identity discrimination and violence in Bessie Head's trilogy (Masters thesis, University of South Africa, 2002). Retrieved from http://www.ujr.unisa.ac.za/bitstream/handle/10500/1236/dissertationpdf?sequence

Milani, A. (September, 2005). Exile and identity: The San Diego seminar and the question of Iranian identity. Retrieved from: http: www.stanford.edu/ amilani/.../exileidentity.pdf

Nachmias, C. F., \& Nachmias, R. (2008). Research methods in the social sciences (5th ed). London: Hodder Education.

Wolf, M., \& Fukari, A. (2007). Constructing sociology of translation. Amsterdam/Philadelphia: John Benjamin Publishing Company.

Said, E. (1984). Reflections on exile. In Ferguson, R (Ed.). Out there .Cambridge: MIT press. 